\title{
EFC2005-86072
}

\section{THERMO-ECONOMIC OPTIMIZATION OF A SOLID OXIDE FUEL CELL, GAS TURBINE HYBRID SYSTEM}

\author{
N. Autissier * \\ Ecole Polytechnique Fédérale de Lausanne (EPFL) \\ Laboratory for Industrial Energy Systems (LENI) \\ $\mathrm{CH}-1015$ Lausanne, Switzerland \\ Email: Nordahl.Autissier@epfl.ch
}

\author{
F.Palazzi \\ F.Marechal \\ J.Van herle D. Favrat \\ Ecole Polytechnique Fédérale de Lausanne (EPFL) \\ Laboratory for Industrial Energy Systems (LENI) \\ $\mathrm{CH}-1015$ Lausanne, Switzerland
}

\section{ABSTRACT}

Large scale power production benefits from the high efficiency of gas-steam combined cycles. In the lower power range, fuel cells are a good candidate to combine with gas turbines. Such systems can achieve efficiencies exceeding 60\%. High temperature Solid Oxide Fuel Cells (SOFC) offer good opportunities for this coupling. In this paper, a systematic method to select a design according to user specifications is presented.

The most attractive configurations of this technology coupling are identified using a thermo-economic multi-objective optimization approach. The SOFC model includes detailed computation of losses of the electrodes and thermal management. The system is integrated using pinch based methods. A thermoeconomic approach is then used to compute the integrated system performances, size and cost. This allows to perform the optimization of the system with regard to two objectives: minimize the specific cost and maximize the efficiency.

Optimization results prove the existence of designs with costs from $2400 \$ / k W$ for a $44 \%$ efficiency to $6700 \$ / k W$ for a $70 \%$ efficiency. Several design options are analysed regarding, among others, fuel processing, pressure ratio or turbine inlet temperature.

The model of a pressurized SOFC- $\mu G T$ hybrid cycle combines a state-of-the-art planar SOFC with a high speed micro gas turbine sustained by air bearings.

\footnotetext{
*Address all correspondence to this author.
}

\section{INTRODUCTION}

For decentralized electricity production, the solid oxide fuel cells (SOFC) have emerged in the last years as an ideal candidate to be combined with gas turbines. This kind of hybrid system takes advantage of the SOFC high operation temperatures to valorize the fuel energy.

Many studies have assessed the feasability and operating conditions of such systems, proposing a variety of design alternatives. The U.S. Department of Energy high efficiency fossil power plant program has demonstrated [1] the feasability of a low cost SOFC-GT system of $220 \mathrm{kWe}$, integrating a Mercury 50 gas turbine and a Siemens Westinghouse SOFC. Such systems achieve efficiencies of $60 \%$ for an expected installation cost of $1170 \$ / k W$. Massardo and Magistri [2] analyzed pressurized and atmospheric systems with efficiencies varying from 65 to $75 \%$. The latter work also presented a thermo-economic analysis of the system components. At the present time, few studies have approached the design of hybrid SOFC-GT systems as an optimization problem. Yi et al. [3] have optimized an internal reforming solid oxide fuel cell and intercooled gas turbine hybrid cycle using analysis tools based on a design of experiments (DOEx) approach. For plants of around $600 \mathrm{MW}$, efficiencies higher than 75\% based on LHV are reached. Marechal et al. [4] have demonstrated a method to optimize PEM fuel cell systems that integrate a micro-gas turbine. The same approach has been applied by Palazzi et al. [5] on SOFC systems and will be applied here for the design of hybrid SOFC microGT. 


\begin{tabular}{|c|c|c|}
\hline$A_{\text {cell }}$ & Single cell area & $m^{2}$ \\
\hline$C_{\text {cell }}$ & Cell cost & $\$$ \\
\hline$C_{c t}$ & Compressor and turbine cost & $\$$ \\
\hline$C_{\text {DriveSpec }}$ & Drive specific cost & $\$ . k W^{-1}$ \\
\hline$C_{h, \text { spec }}$ & Stack Housing specific cost & $\$ . c m^{-2}$ \\
\hline$C_{F C, \text { spec }}$ & Cell surface specific cost & $\$ . c m^{-2}$ \\
\hline$C_{F C \text { stack }}$ & Fuel cell cost & $\$$ \\
\hline$C_{\text {microGT }}$ & Complete $\mu$ GT cost & $\$$ \\
\hline$C_{V P}$ & Volume purchase cost & $\$$ \\
\hline LHV & Lower heating value & $k J \cdot k^{-1}$ \\
\hline$N_{\text {stack }}$ & Number of stacks & - \\
\hline$P_{\text {shaft }}$ & Available mechanical power & $\mathrm{kW}$ \\
\hline$P_{\text {elec }}$ & Net electrical power & $\mathrm{kW}$ \\
\hline$P_{C, \text { out }}$ & Compressor outlet pressure & $\mathrm{Pa}$ \\
\hline$R$ & Gas constant & $J . \mathrm{kmol}^{-1}$ \\
\hline$T_{\text {fuelcell }}$ & Fuel cell temperature & $\mathrm{K}$ \\
\hline$T_{\text {exhaust }}$ & Exhaust gas temperature & $\mathrm{K}$ \\
\hline$T_{r}$ & Reformer temperature & $\mathrm{K}$ \\
\hline$c_{i}$ & Polynomial coefficients & - \\
\hline$d$ & Wheel diameter & $\mathrm{m}$ \\
\hline$d_{s}$ & Specific Diameter & $\mathrm{m}$ \\
\hline$e_{i s}$ & Adiabatic Head & $J . k^{-1}$ \\
\hline$f_{\text {act }}$ & Actualization factor & - \\
\hline$f_{B M}$ & Bare Module factor & - \\
\hline$f_{h s}$ & Stack housing surface factor & - \\
\hline$f_{\text {pressure }}$ & Pressure factor & - \\
\hline$i$ & Current density & A. $m^{-2}$ \\
\hline$n_{s}$ & Specific speed & $m \cdot s^{-1}$ \\
\hline$P$ & Pressure & $\mathrm{Pa}$ \\
\hline$T$ & Temperature & $\mathrm{K}$ \\
\hline in, out & Index for inlet or outlet & - \\
\hline$t$ & Index for turbine & - \\
\hline$c$ & Index for compressor & - \\
\hline
\end{tabular}

$$
\begin{array}{lll}
\eta_{c} & \text { Compressor efficiency } & - \\
\mu & \text { Fuel utilization } \\
\lambda & \text { Air excess ratio } & - \\
\gamma & \text { Ratio of specific heats } & -
\end{array}
$$

\section{PROCESS DESIGN THROUGH THERMO-ECONOMIC OPTIMIZATION}

The identification of the most interesting system design is performed using a thermo-economic optimization approach. The methodology proceeds with two main steps: modeling the system for a set of fixed decision variables and optimizing their values.

\section{Modeling the system}

For system design the model is used to represent the influence of the design decisions on the system performances. The model involves a number of state variables describing the physical state of the system as well as its cost and its performances. The state variables are divided into two categories: the decision variables, that are determined by the user, and the dependent variables that are computed by solving the model equations once the values of the decision variables are established.

In the present framework, the system model is divided into three sub-models (fig. 1):

1. the energy flow model,

2. the heat and power integration model,

3 . the thermo-economic performance evaluation.

The energy flow model (1) computes the thermodynamic performances of the chemical and mechanical conversion in the system and defines the corresponding energy requirements as a function of the decision variables. For this step a commercial process modeling software is used (BELSIM-VALI).

The heat and power integration model (2) is an optimization model that maximizes the combined production of heat and power while solving the heat cascade and the energy balance of the plant. This defines the minimum of energy required and sets the basis to design the heat exchanger network. This step is modeled by EASY, an energy integration tool under development at LENI which implements the methods developed in [6].

Using the results of the energy flow and the heat and power integration models, the size and characteristics of the major equipments in the system are computed (3). This allows for determining the cost and the performances of the system. This part of the model is computed in Matlab.

The model of a system can then be used to study a particular configuration by performing sensitivity analyses on various 
parameters, or it can be used to optimize the value of the dependent variables according to the user preferences as detailed in the following paragraph.

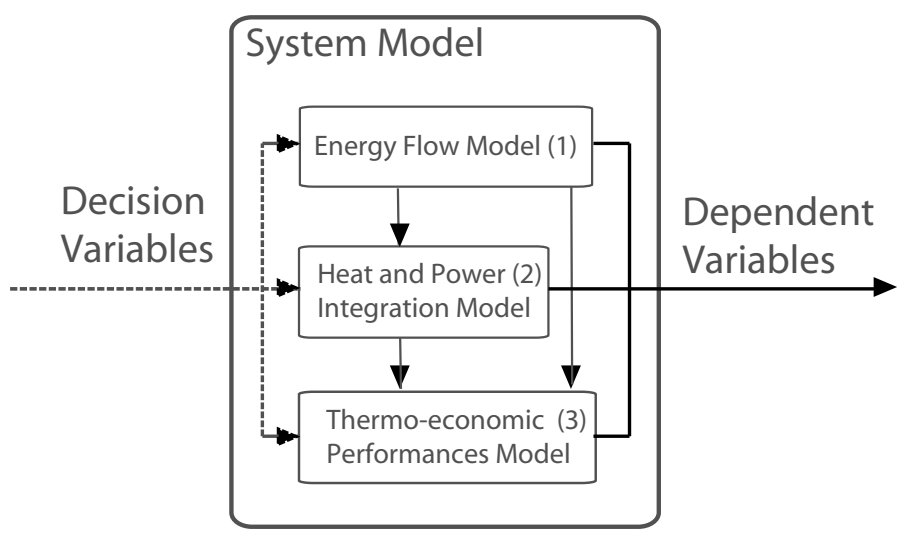

Figure 1. SYSTEM MODEL STRUCTURE

\section{Optimization}

The objectives to reach, when designing a system, are ruled by the constraints imposed on the engineer. The cost of the final system is always an important factor for the realization of such a plant. Other important factors are often related to the impact of the system on the environment. Hence, while trying to minimize the cost of the plant, the engineer will try to minimize the emissions, or the noise, or to maximize the efficiency of the plant.

We focus here on thermo-economic optimization that considers two objectives: (i) the maximization of the system electrical efficiency and (ii) the minimization of the investment cost. The search space of the optimization is defined by the decision variables and their bounds.

The solution of such a multi-objective optimization problem is a set of points in the decision variables space that express the possible tradeoff between the objectives. In the domain of the objective functions, this tradeoff is represented by the Pareto frontier. This curve represents the set of non dominated solutions, which delimits the unfeasible domain from the feasible but sub-optimal one.

In the present methodology, the resolution of the optimization is performed using an Evolutionary Algorithm MOO (MultiObjective Optimizer) which has been developed at LENI by Leyland [7] and Molyneaux [8]. Evolutionary Algorithms are heuristic methods that base the optimization procedure on the exploration of the search space, thus allowing to optimize a non-linear and non-continous system of equations. MOO uses clustering techniques to preserve the existence of several local optima.

The modeling and optimization framework described above is integrated into OSMOSE, a Matlab based software under development at LENI for the design and the optimization of integrated energy systems. It has been used by the authors to study the design of a combined PEM fuel cell - gas turbine system [4] and of a SOFC system [5] and is described in detail in [4]. In the present paper the methodology is applied to the design of a hybrid SOFC-GT system as detailed in the following paragraphs.

\section{MODEL DESCRIPTION}

A steady-state model of a hybrid SOFC-GT system has been established to engineer $50 \mathrm{~kW}$-class systems. The system model is subdivided (fig. 2) into four sub-systems : fuel processing, fuel cell, post-combustion and turbine. Each sub-system includes energy flow, heat exchange network and thermo-economic performance models. A simple flow chart was chosen without recirculation of depleted anode gas.

\section{Fuel processing model}

The system is fed with natural gas. Several options are available for fuel processing : steam reforming, partial oxidation, or a combination of both as in an auto-thermal reformer [5]. Reforming can be partially internal. The reactor is a shell and tube reactor, whose thermo-economic model is detailed in [4]. The water pump, fuel and air blowers are electrically driven. The electrical power needed is provided by the fuel cell and turbine system.

\section{Solid oxide fuel cell model}

The SOFC model is based on the model developed by Van herle [9]. Planar technology is assumed, with anode supported cells, thin electrolyte, composite LSM/YSZ cathode and metallic interconnectors. The fuel cell is composed of multiple 100 cells stacks. A cell area of $200 \mathrm{~cm}^{2}$ has been chosen, combining state-of-the-art fabrication and stack assembly capabilities. The electro-chemical model includes anode and cathode diffusion losses, ohmic and activation losses.

The model includes the possibility of internal reforming. The fuel cell is maintained at $1073 \mathrm{~K}$. This temperature is a tradeoff, high enough to allow good operation of anode supported cells with LSM cathode and not too high to limit degradation of the metallic interconnects. A limit of $100 \mathrm{~K}$ is fixed for the maximum temperature difference across the fuel cell to avoid cracks due to thermal gradients. If the heat generated inside the fuel cell leads to temperature differences higher than $100 \mathrm{~K}$, energy will have to be evacuated by heat exchange.

The cell potential is computed as a function of inlet gas concentrations, fuel utilization and current density. The number of 


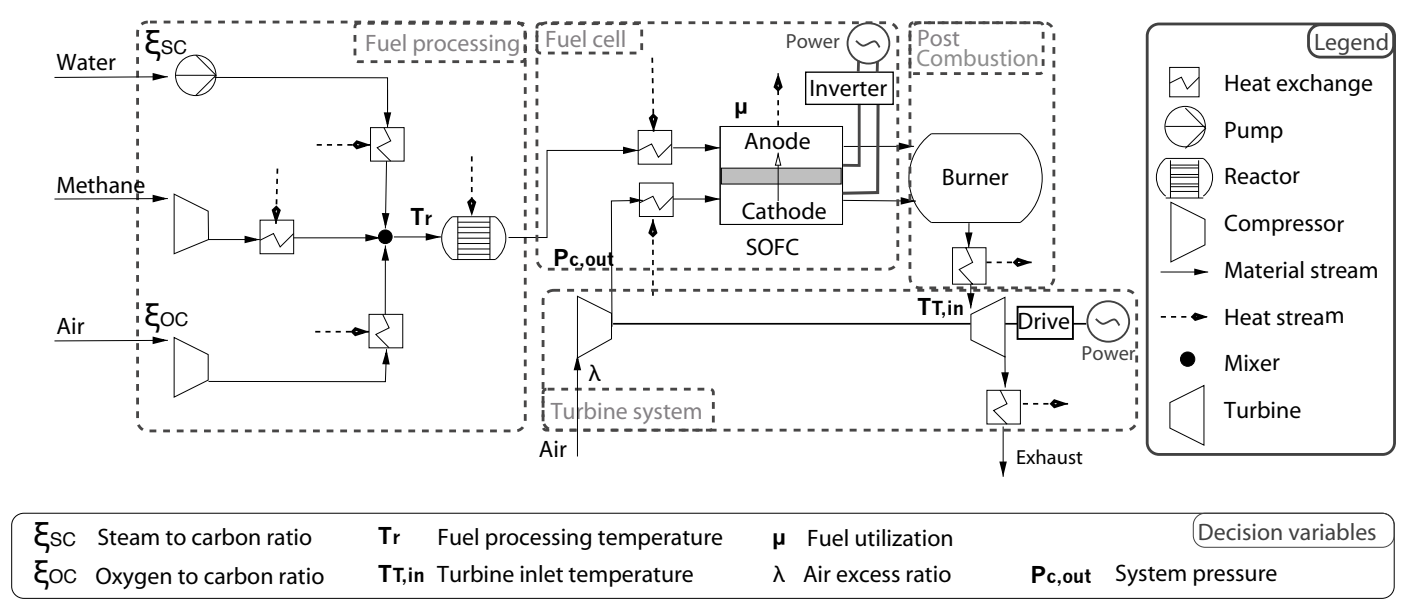

Figure 2. SYSTEM FLOWSHEET WITH DECISION VARIABLES USED FOR OPTIMIZATION

cells is subsequently determined to fulfill the required power.

The fuel cell cost model (table 2) has been calibrated using a study on cell specific costs [10]. It includes the housing price for each 100 cell stack, and the price of the pressurized enclosure [11]. Parameters are given in table 1

Table 1. COMPRESSOR AND TURBINE EQUATIONS

\begin{aligned} &$e_{i s, t}=\frac{\gamma}{(\gamma-1)} \cdot r \cdot T_{\text {in }} \cdot\left(1-\left(\frac{P_{\text {out }}}{P_{\text {in }}}\right)^{\frac{\gamma-1}{\gamma}}\right) \\ & \log _{10}\left(d_{s, t}\right)=0.3932 \cdot n_{s}^{-0.4789} \\ & d_{t}=\sqrt{\frac{\dot{m}}{\rho}} \cdot \frac{d_{s}}{e_{i s}^{0.25}} \\ & \eta_{t}=\sum_{i=1}^{5} c_{i} n_{s}^{i} \\ & e_{i s, c}=\frac{\gamma}{(\gamma-1)} \cdot r \cdot T_{\text {in }} \cdot\left(\left(\left(\frac{P_{\text {out }}}{P_{\text {in }}}\right)^{\frac{\gamma-1}{\gamma}}-1\right)\right. \\ & n_{s}=\frac{\omega \cdot \sqrt{\frac{\dot{m}}{\rho}}}{e_{i s}^{0.75}} \\ & \log _{10}\left(d_{s}\right)=0.5228 \cdot n_{s}^{-0.4509} \\ & d=\sqrt{\frac{\dot{m}}{\rho}} \cdot \frac{d_{s}}{e_{i s}^{0.25}} \\ & \eta_{c}=\sum_{i=0} c_{i} n_{s}^{i} \\ & C_{\text {Drive }}=P_{\text {shaft }} \cdot C_{\text {DriveSpec }} \\ & C_{\text {microGT }}=f_{\text {actualization }} \cdot\left(C_{\text {Drive }}+C_{c t}\right) \\ &$\hline\end{aligned}

Table 2. SOFC COST FUNCTIONS

$$
\begin{aligned}
C_{\text {cell }} & =A_{\text {cell }} \cdot C_{\text {spec }} \\
N_{\text {stack }} & =\frac{N_{\text {cells }}}{N_{\text {cells }}^{\text {max }}} \\
C_{\text {VolumeBareModule }} & =C_{\text {VolumePurchase }} \cdot f_{B M} \cdot f_{\text {pressure }} \\
C_{\text {volumepurchase }} & =10^{K_{1}+K_{2} \log _{10}(\text { ThermalLoad })} \\
C_{F C \text { stack }} & =f_{B M} \cdot\left(C_{\text {cell }} \cdot N_{\text {cells }}+2 \cdot N_{\text {stack }} \cdot A_{\text {cell }} \cdot f_{\text {hs }} \cdot C_{h, \text { spec }}\right) \\
C_{f c} & =f_{\text {actualization }} \cdot\left(C_{\text {VolumeBareModule }}+C_{F C \text { stack }}\right)
\end{aligned}
$$

\section{Air compressor and turbine models}

The air needed for the fuel cell cathode is provided by a centrifugal compressor. Mechanical power is generated by a turbine, coupled with the compressor on the same shaft. No gearbox is employed, electricity required or produced is controlled by the electronics of the high speed generator. As the considered target power range is below $50 \mathrm{~kW}$, high rotational speeds (over 100 $000 \mathrm{rpm}$ ) are required to obtain high efficiencies. In this case air bearings [12] are a promising technology considering their reduced size and their lower parasitic losses compared to magnetic bearings. A similarity concept is used for a preliminary design of the turbine and the compressor [13]. In this case, the design characteristics are not fixed a priori but determined based on empirical similarity laws for optimum efficiency. Taking the compressor as an example (fig. 3), a polynomial function defining the maximum efficiency for a given specific speed is determined (dashed curve). The thermodynamic models and polynomial coefficients are given in table 1.

For a small scale turbine no cooling system can be easily implemented. The limiting operating temperature is therefore 


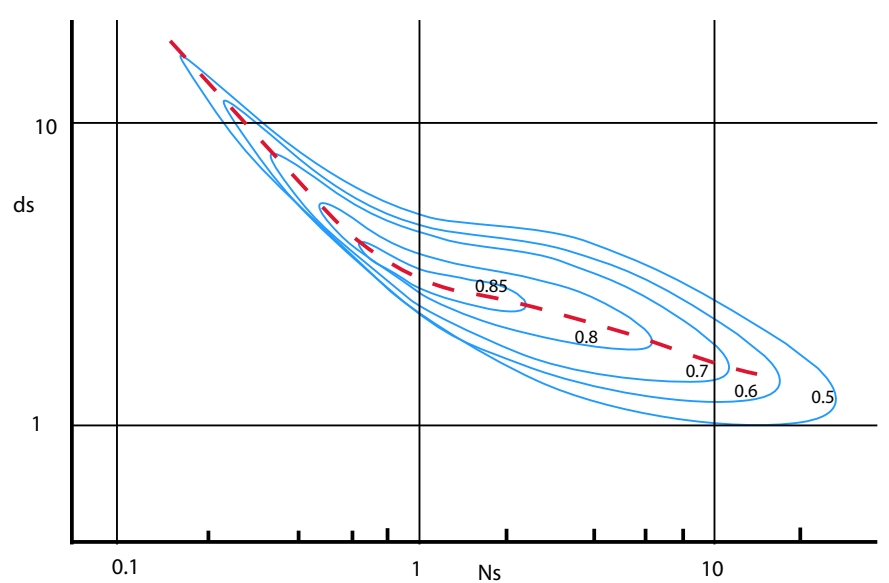

Figure $3 . n_{s} d_{s}$ DIAGRAM FOR SINGLE STAGE COMPRESSOR FROM BALJE [13]

given by the properties of the high temperature materials employed. Kimijima [14] fixes technological limits for an uncooled $\mu$-turbine with ceramic head around $1420 \mathrm{~K}$. In the model, the maximum operating temperature is fixed at $1350 \mathrm{~K}$. Another technological constraint is given by the pressure ratio. A two stages compressor would be needed for pressure ratios higher than 6 to maintain high efficiencies. This model considers only one stage compression, limiting therefore the pressure ratio under 6.

Gases are supposed to exit the system at a temperature of $373 \mathrm{~K}$ through a chimney to the environment. The remaining energy in flue gases is lost.

\section{Integrated heat exchange system model}

The optimal heat exchanger network is based on the minimization of the exergy losses. Heat exchange is assumed with a minimum temperature difference of $60 \mathrm{~K}$. The costs of the heat exchangers are computed based on the cumulated exchange area [11], as described in [4]. Figure 4 displays the corrected composite curves $\left(T \pm \frac{\Delta T_{\min }}{2}\right)$ of one system design configuration, leading to a system efficiency of $64 \%$. On this graphic, the following elements can be distinguished.

1. Hot gases from turbine outlet to chimney

2. Fuel Cell excess heat

3. Turbine inlet temperature

4. Post-combustion temperature

5. Fuel Cell inlet temperature

6. Water evaporation for fuel processing

7. Cooling water

In this particular case, the minimum pinch temperature value is not reached and the post-combustion gases have to be cooled

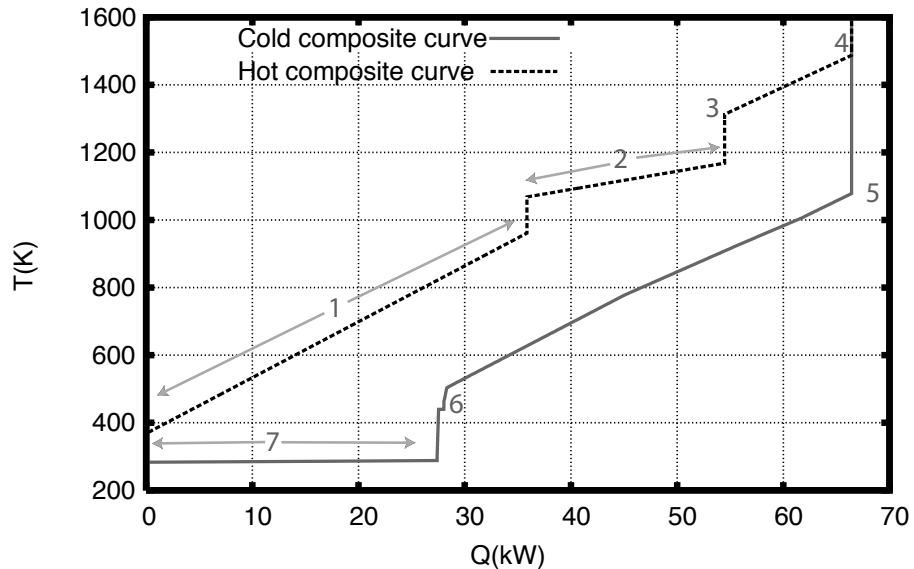

Figure 4. HOT AND COLD COMPOSITE CURVE

upstream of the turbine between 4 and 3. Ohmic losses and nonohmic losses in the fuel cell produce heat that has to be extracted to avoid high gradients as discussed. Between 6 and 5, air and fuel need to be heated from compressor outlet temperatures to the fuel processing temperature and then to the fuel cell inlet temperature. The heat evacuated from the system in represented by 7 . In this case, $27 \mathrm{~kW}$ have to be evacuated at temperatures between $800 \mathrm{~K}$ and $400 \mathrm{~K}$. This shows an opportunity to further valorize this energy as high temperature heat.

\section{Post combustion model}

Post combustion produces hot gases to be cooled down to the inlet temperature of the turbine (segment 4 to 3 ).

\section{RESULTS}

The model described above has been used to perform a thermo-economic optimization, for a system producing $30 \mathrm{~kW}$ net electrical power. The two objectives are: (1) minimization of the investment cost and (2) maximization of the electrical efficiency. The cost of the system is the sum of the costs of all the components. The electrical efficiency of the system is defined as the ratio between the net output electrical power and the energy corresponding to the lower heating value (LHV) of the entering fuel. The fixed parameters and the decision variables are given in table 3.

The evolutionary algorithm we use is multimodal which means that it can identify clusters characterized by similarities in technological design. In figure 5 the optimum solutions corresponding to 4 different clusters are grouped on 3 pareto curves. For each family of solutions, the pareto line divides the feasible domain (above) from the unreachable domain (below).

Along the pareto curves, optimal solutions go from the lowest cost and low efficiency to the more performing but more ex- 
Table 3. DECISION VARIABLES FOR OPTIMIZATION

\begin{tabular}{lcc} 
Name & Range & Unit \\
\hline$T_{\text {reformer }}$ & {$[800 ; 1100]$} & $\mathrm{K}$ \\
$\mu$ & {$[0.5 ; 0.80]$} & - \\
$P_{c, \text { out }}$ & {$[1.1 ; 6]$} & bar \\
$\xi_{O C}$ & {$[0.001 ; 0.5]$} & - \\
$\xi_{S C}$ & {$[0.4 ; 4]$} & - \\
$T_{T, \text { in }}$ & {$[800 ; 1350]$} & $\mathrm{K}$ \\
$\lambda$ & {$[1.5 ; 5]$} & - \\
$\mathrm{i}$ & {$[1000 ; 5000]$} & $A / m^{2}$ \\
\hline
\end{tabular}

Table 4. CONSTANTS FOR OPTIMIZATION

\begin{tabular}{lcc} 
Name & Value & Unit \\
\hline$A_{\text {cell }}$ & 200 & $\mathrm{~cm}^{2}$ \\
$T_{\text {fuelcell }}$ & 1073 & $\mathrm{~K}$ \\
$T_{\text {exhaust }}$ & 373 & $\mathrm{~K}$ \\
$n_{s, c}$ & 0.6 & $\mathrm{~m} . \mathrm{s}^{-1}$ \\
$C_{\text {spec }}$ & 0.1442 & $\$ / \mathrm{cm}^{2}$ \\
$C_{h, \text { spec }}$ & 0.3095 & $\$ / \mathrm{cm}^{2}$ \\
$K_{1}$ & 2.5689 & - \\
$K_{2}$ & 0.8067 & - \\
$C_{F C, s p e c}$ & 0.1442 & $\$ / \mathrm{cm}^{2}$ \\
\hline
\end{tabular}

pensive ones.

Clusters 2 and 3 are characterized by a high fuel utilization (see fig. 6) and a pressure ratio between 5.5 and 6. Those values correspond to the upper bound of the range considered. The cluster 2 differs from cluster 3 by a vapor to carbon ratio between 0.4 and 0.5 whereas in cluster 3 values increase to 1.8 (see fig.8).

Solutions in cluster 4 have an oxygen to carbon ratio of around 0.1 (compared to 0.02 for the other clusters). The cluster 1 is characterized by a lower pressure ratio (between 3.7 and 4.7) with advantages of easier wheel design and lower strength and sealing requirements. The current density allows to trade off design with non modeled performances like degradation or lifetime expectation. From figure 9, it can be seen that low current density (below $0.3 \mathrm{~A} / \mathrm{cm}^{2}$ ) will be needed to reach high efficiencies. This is explained by the characteristics of the selected cell and leads to a cell potential from 0.65 to 0.85 (see fig.7). The
Table 5. TURBINE AND COMPRESSOR CONSTANTS

\begin{tabular}{lll|lll}
\hline$c_{i}$ & turbine & compressor & Name & Value & Unit \\
\hline$c_{5}$ & 6.6944 & 0.1851 & $C_{c t}$ & 500 & $\$$ \\
$c_{4}$ & -18.61 & -1.2968 & $C_{\text {DriveSpec }}$ & 200 & $\$ / k W$ \\
$c_{3}$ & 20.56 & 3.5183 & $f_{B M}$ & 2.7 & - \\
$c_{2}$ & -12.402 & -4.6688 & $f_{h s}$ & 1.5 & - \\
$c_{1}$ & 4.1017 & 3.0186 & $f_{\text {pressure }}$ & 1 & - \\
$c_{0}$ & 0.3366 & 0.1168 & & &
\end{tabular}

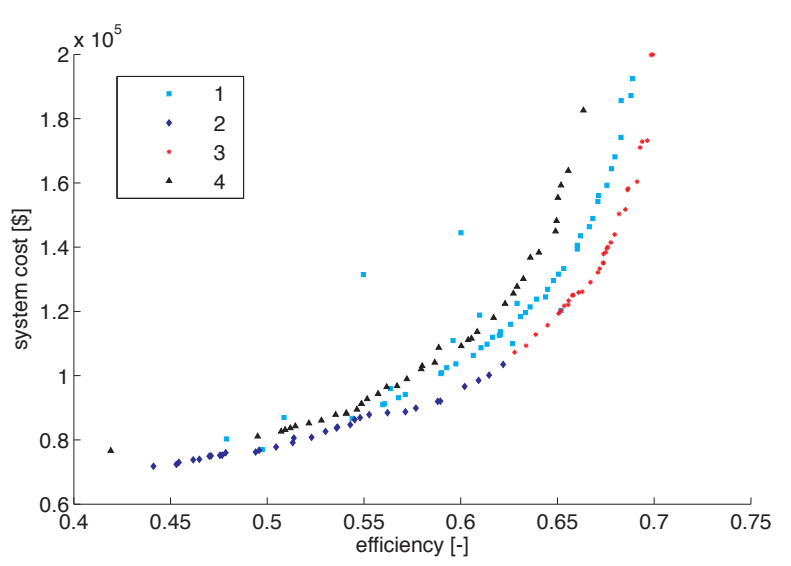

Figure 5. EFFICIENCY vs SYSTEM COST FOR 30KWe

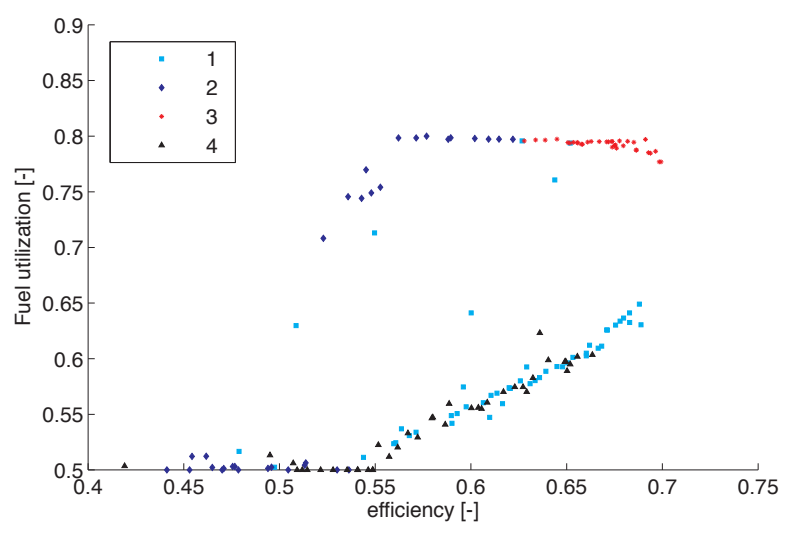

Figure 6. EFFICIENCY vs FUEL UTILIZATION FOR 30KWe

number of cells varies as a function of the current density from 275 to 1600 . It is also interesting to note that some high efficiency systems are found with a fuel utilization of around $60 \%$ (fig. 6). In this case, the remaining fuel is being used to drive the gas turbine. The rotational speed of compressor and turbine 


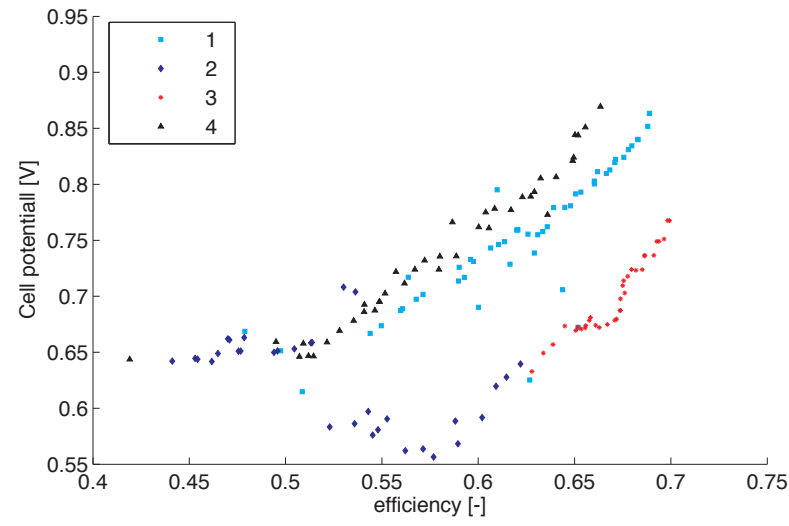

Figure 7. EFFICIENCY vs CELL POTENTIAL, $30 \mathrm{kWe}$ CASE

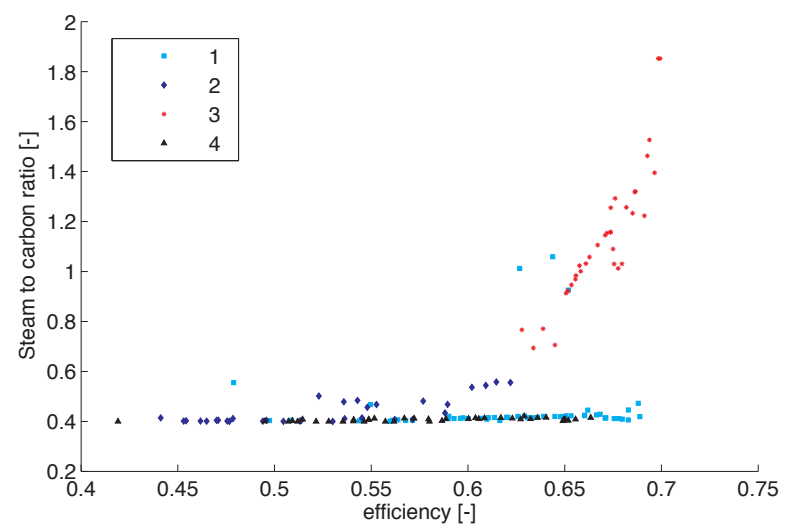

Figure 8. EFFICIENCY vs STEAM TO CARBON RATIO, $30 \mathrm{kWe}$ CASE

varies between 200000 and $340000 \mathrm{rpm}$.

Figure 10 displays the production of the gas turbine for the different solutions. The contribution of mechanical power varies from $20 \%$ to $40 \%$ of the total electricity produced.

The turbine inlet temperature is not a relevant decision variable in this case because all solutions are close to the upper limit, a behavior which is understandable with a model in which turbine cost is not temperature dependent.

Figure 11 shows the link between the air excess ratio and the efficiency.

The heat exchangers estimated costs (fig. 12) account for approximatively one third of the total cost of the system. It should be mentioned that this estimate does not account for the detailed design of the heat exchange network.

The composite curves of the most efficient solution are presented in figure 13. The reforming process, converting $89 \%$ of methane, occurs mainly upstream of the fuel cell. It defines a cold stream at high temperature (end of the cold composite curve). Therefore excess heat needs to be extracted from the fuel

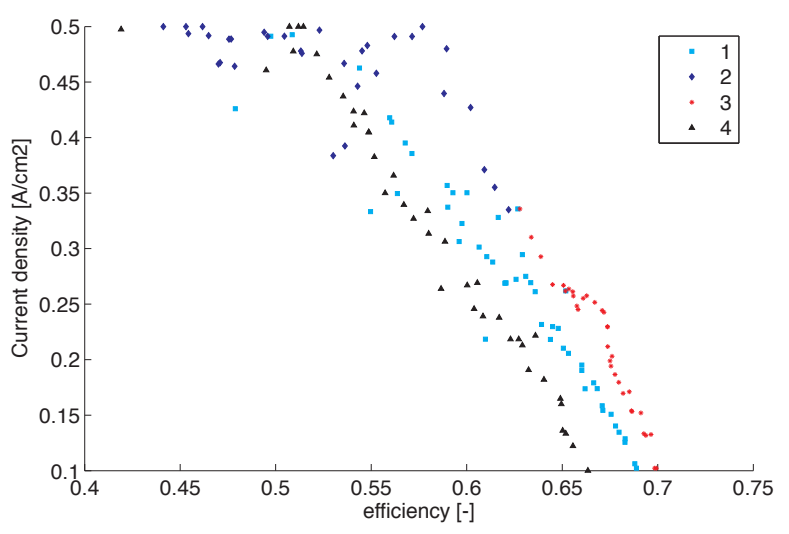

Figure 9. EFFICIENCY vs CURRENT DENSITY, $30 \mathrm{kWe}$ CASE

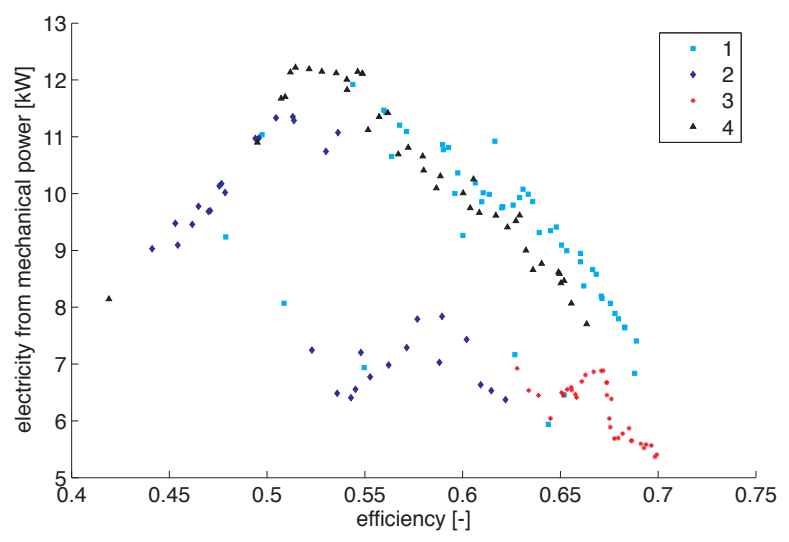

Figure 10. EFFICIENCY vs ELECTRICITY FROM MECHANICAL POWER, $30 \mathrm{kWe}$ CASE

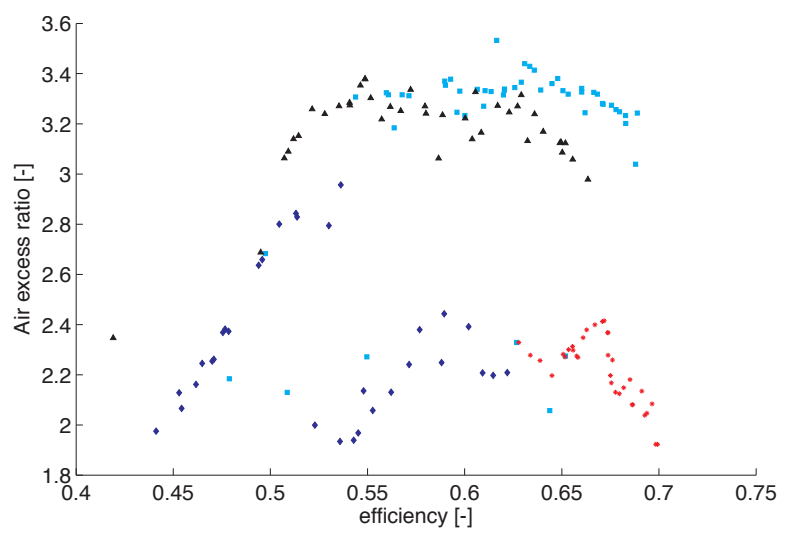

Figure 11. EFFICIENCY vs AIR EXCESS RATIO, $30 \mathrm{kWe}$ CASE 


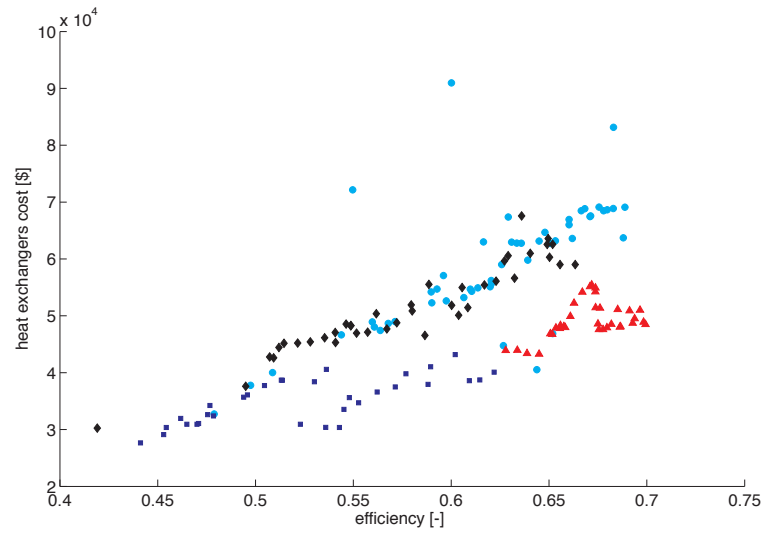

Figure 12. EFFICIENCY vs HEAT EXCHANGER COST, $30 \mathrm{kWe}$ CASE

cell to maintain an acceptable temperature difference. A pinch point is created at low temperature by the steam production for the fuel processing. As discussed in [4], this pinch point could be avoided by adding a natural gas humidification device. In figure 14, the hot and cold composite curves of the most efficient system configuration from cluster 1 are presented. In this case, only $44 \%$ of methane is converted in the fuel processing, thus internal reforming takes place on the fuel cell anode, absorbing the heat released by the electro-chemical reaction. This shows that systems with drastically different design may lead to very similar overall performances.

Several solutions imply a heat exchange between the post combustion gases and the gas entering the fuel cell, as seen at the top right part of the composites in figures 13 and 14. In practice such a heat exchanger will most likely be replaced by a direct combustion of the depleted anode gas at a lower temperature with gas recirculation schemes. We assumed that the fuel processing is integrated with the fuel cell in such a way that the post-combustion will create the radiative zone of the steam reforming reactor.

\section{CONCLUSION AND FURTHER WORK}

A design methodology based on a multi-objective optimization approach has been applied to a pressurized SOFC- $\mu \mathrm{GT}$ hybrid cycle. Such a cycle combines a state-of-the-art planar SOFC with a high speed micro gas turbine sustained by air bearings. Process integration techniques are used to compute the integrated system performances. Thermo-economic models of each equipment part allow to estimate the investment costs of the system. The use of a two objective optimization framework allows to identify the trade-offs between maximum efficiency and minimum investment costs. The design example is a unit with $30 \mathrm{kWe}$ output power. Solutions specific costs range from $2400 \$ / k W$ with a $44 \%$ efficiency to $6700 \$ / k W$ and $70 \%$ efficiency. The

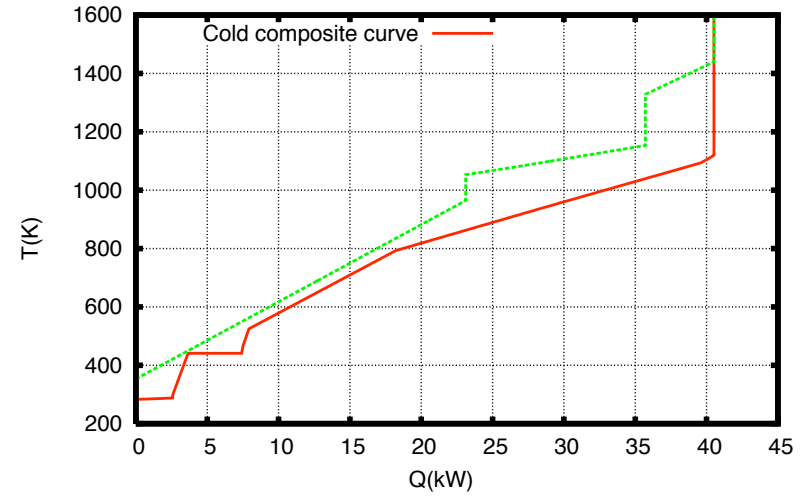

Figure 13. COMPOSITE CURVES CLUSTER $3 \eta=70 \%$,

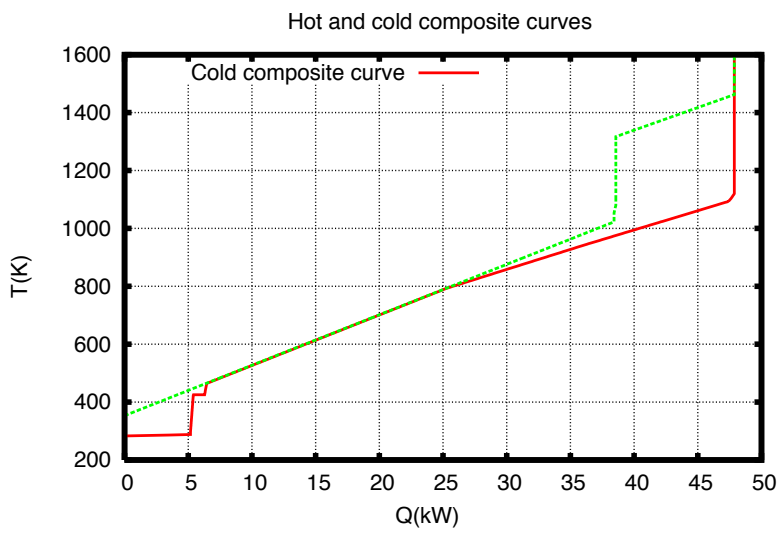

Figure 14. COMPOSITE CURVES CLUSTER $1 \eta=69 \%$,

multi-objective optimization strategy allows identifying families of optimal solutions, that gives hints to the design engineers.

The capability of the algorithm to identify different clusters allows to keep sub-optimal interesting configurations as exemplified by the low pressure ratio solutions of cluster 1 .

High system efficiencies can be obtained with low fuel utilization.

Many solutions imply some gas cooling before turbine inlet, corresponding to a heat exchange between combustion gases and process streams (air preheating or steam reforming reactor). In practice, the air preheating is realized by direct combustion leading to gas recirculation schemes.

As future work, the following improvements are foreseen:

For turbine technology, the price of material (nickel based alloys or ceramics) for the wheel should be introduced to modify unit cost with increasing temperature.

Another interesting way to lower the post-combustion temperature, is to inject water in the combustion chamber resulting in an increased volume flow. As a by-product more mechanical 
power should be recovered at the turbine.

As stressed in [9], a criteria defining the risk of carbon deposition could be integrated to ensure safe operation of the reformer and stack components. Characteristics of tubing material (catalytic activity, price) should be introduced to compare more accurately solutions with a pre-reformer and various methane content at the fuel cell entrance.

Approaching the pressurized SOFC-GT system design with an optimization procedure, the engineer is able to explore a broad range of design alternatives, and quickly identify the most attractive system configurations.

\section{ACKNOWLEDGMENT}

The authors acknowledge the financial support of the Swiss Federal Office of Energy contract nb. 100995/151158, of CTI6649.3 IWS-IW and of OFES 03.0170-6 (EU project SES6CT-2003-502612, REAL-SOFC )

\section{REFERENCES}

[1] Lundberg, W. L., Veyo, S. E., and Moeckel, M. D., 2003. "A high-efficiency solid oxide fuel cell hybrid power system using the mercury 50 advanced turbine systems gas turbine". Journal of Engineering for Gas Turbines and PowerTransactions of the Asme, 125(1), pp. 51-58.

[2] Massardo, A. F., and Magistri, L., 2003. "Internal reforming solid oxide fuel cell gas turbine combined cycles (irsofc-gt) - part ii: Exergy and thermoeconomic analyses". Journal of Engineering for Gas Turbines and PowerTransactions of the Asme, 125(1), pp. 67-74.

[3] Yi, Y. F., Rao, A. D., Brouwer, J., and Samuelsen, G. S., 2004. "Analysis and optimization of a solid oxide fuel cell and intercooled gas turbine (sofc-icgt) hybrid cycle". Journal of Power Sources, 132(1-2), pp. 77-85. Article 820VL English Times Cited:2 Cited References Count:13.

[4] Marechal, F., Palazzi, F., Godat, J., and Favrat, D., 2004. "Thermo-economic modelling and optimisation of fuel cell systems". Fuel Cells : From Fundamentals to Systems,, 5(1), pp. 5-24.

[5] Palazzi, F., Autissier, N., Maréchal, F., and Van herle, J., 2005. "A methodology for thermo-economic modeling and optimization of sofc systems". Chemical Engineering Transactions, 7, pp. 13-18.

[6] Marechal, F., and Kalitventzeff, B., 1998. "Process integration: Selection of the optimal utility system.". Computers \& Chemical Engineering, 22, pp. S149-S156.

[7] Leyland, G. B., 2002. "Multi-objective optimisation applied to industrial energy problems". Phd, Ecole Polytechnique Federale de Lausanne.
[8] Molyneaux, A., 2002. “A practical evolutionary method for the multi-objective optimisation of complex energy systems, including vehicle drivetrains". Phd, Ecole Polytechnique Federale de Lausanne.

[9] Van herle, J., Marechal, F., Leuenberger, S., Membrez, Y., Bucheli, O., and Favrat, D., 2004. "Process flow model of solid oxide fuel cell system supplied with sewage biogas". Journal of Power Sources, 131(1-2), pp. 127-141.

[10] Molinelli, M., 2005. Internal communication.

[11] Turton, R., 1998. Analysis, Synthesis, and Design of Chemical Processes. Prentice Hall PTR, Upper Saddle River, NJ, USA.

[12] Schiffmann, J. ; Favrat, D., 2005. "Theoretical design of a high-speed low power radial turbocompressor". In 6th European Turbomachinery Conference, March, Lille, France.

[13] Balje, O., 1981. Turbomachines, guide to design, selection and theory. Wiley-Interscience.

[14] Kimijima, S., 2004. "Prospect of sofc-mgt hybrid system". In International Workshop on fuel cell hybrid systems, S. I. of technology, ed., pp. 72-79. 